\title{
A novel PI3K inhibitor alleviates fibrotic responses in fibroblasts derived from Peyronie's plaques
}

\author{
KYUNG HEE JUNG $^{1 *}$, YE-LIM RYU ${ }^{1 *}$, HEE-SEUNG LEE ${ }^{1}$, HYUNSEUNG LEE ${ }^{1}$, MI KWON SON ${ }^{1}$, \\ HONG HUA YAN ${ }^{1}$, SANG-WON HONG ${ }^{1}$, JI-KAN RYU ${ }^{2}$, SUNGWOO HONG ${ }^{3}$, \\ JUN-KYU SUH ${ }^{2}$ and SOON-SUN HONG ${ }^{1}$ \\ ${ }^{1}$ Department of Biomedical Sciences, ${ }^{2}$ National Research Center for Sexual Medicine, College of Medicine, \\ Inha University, Incheon $400-712 ;{ }^{3}$ Department of Chemistry, Korea Advanced Institute \\ of Science and Technology (KAIST), Daejeon 305-701, Republic of Korea
}

Received January 23, 2013; Accepted March 22, 2013

DOI: 10.3892/ijo.2013.1905

\begin{abstract}
Peyronie's disease (PD) is fibrosis localized in the tunica albuginea that is characterized by penile deformity and curvature. The pathogenesis of this disease remains unclear even though transforming growth factor- $\beta$ (TGF- $\beta$ )/smad signalling has been reported to be associated with PD. Recent studies have shown that phosphoinositide 3-kinase (PI3K)/Akt signalling regulates fibrotic responses including collagen synthesis and cell proliferation. Thus, we synthesized HS-173, a novel PI3K inhibitor, and determined whether this compound has anti-fibrotic effects on PD-derived primary fibroblasts. In this study, we found that HS-173 inhibited the growth of fibroblasts in a dose-dependent manner and induced apoptosis. In addition, HS-173 reduced the expression of $\alpha$-smooth muscle actin ( $\alpha$-SMA), vimentin, PAI-1, fibronectin, collagen type I, collagen IV and TGF- $\beta$ activated smad2/3 in PD-derived primary fibroblasts. HS-173 blocked the PI3K/Akt signalling pathway by decreasing the activation of Akt, mTOR and P70S6K. Our results showed that HS-173 suppressed fibrotic responses such as cell proliferation and collagen synthesis by blocking PI3K/Akt signalling in PD-derived primary fibroblasts. Our findings provide molecular insights into the potential therapeutic
\end{abstract}

Correspondence to: Professor Soon-Sun Hong, Department of Biomedical Sciences, College of Medicine, Inha University, 3-ga, Sinheung-dong, Jung-gu, Incheon 400-712, Republic of Korea

E-mail: hongs@inha.ac.kr

Dr Jun-Kyu Suh, National Research Center for Sexual Medicine and Department of Urology, College of Medicine, Inha University, 3-ga, Sinheung-dong, Jung-gu, Incheon 400-712, Republic of Korea

E-mail: jksuh@inha.ac.kr

*Contributed equally

Key words: Peyronie's disease, HS-173, fibrosis, phosphoinositide 3-kinase/Akt, collagen action of HS-173 through targeting the PI3K/Akt pathway in PD-derived fibroblasts and demonstrated that HS-173 could be used as a pharmacological agent for treating other fibrotic diseases.

\section{Introduction}

Peyronie's disease (PD) is an acquired idiopathic localized fibrosis of the penis involving the tunica albuginea of the corpus cavernosum. This condition not only gives rise to palpable plaques in the penis or painful erection but also results in penile curvature, deformities or sexual dysfunction $(1,2)$. Although PD once was thought to be a rare disorder, epidemiologic studies showed a prevalence rate of 3.2-8.9\% among adult men $(1,3)$. Because of our incomplete understanding of the pathogenesis of $\mathrm{PD}$, however, management of $\mathrm{PD}$ remains a therapeutic dilemma in sexual medicine. Currently, surgical intervention is the only effective treatment for this condition, and most available medical treatments have not been proven to be definitively efficacious. Thus, develop of novel and effective medical therapies for PD is required.

Fibrosis is a main pathological manifestation of PD, usually caused by proliferation of fibroblasts and accumulation of various extracellular matrix (ECM) progresses forming plaques or even ectopic calcification that appear as scars and impede expansion of the tunica albuginea during erection $(4,5)$. Until now, involvement of transforming growth factor (TGF)- $\beta$ has been thought to play an important role in PD-related fibrosis (6) and is also known to be upregulated in both human PD plaques and animal PD models $(7,8)$. The binding of active TGF- $\beta$ to its receptor triggers several signalling cascades, including the well-characterized smad and phosphotidylinositol-3-kinase (PI3K)/Akt pathways $(9,10)$. In particular, the PI3K/Akt pathway has been implicated in the control of numerous cellular processes including cell proliferation, survival and inflammation $(11,12)$. PI3K first activates Akt and subsequently increases the expression of downstream proteins including mammalian target of rapamycin (mTOR) and P70S6K. Recently, increasing evidence has shown that the PI3K/Akt pathway effectively 
regulates fibrogenic responses such as ECM remodeling and the proliferation of various types of fibroblasts $(11,13)$. Indeed, blocking PI3K activity has been reported to inhibit collagen expression and the proliferation of fibroblasts such as hepatic stellate cells $(14,15)$, where the inhibition of Akt has also been found to be associated with interruption of fibroblast proliferation/differentiation and collagen type I transcription. Likewise, disturbance of mTOR/P70S6K suppresses fibroblast proliferation (14,16-18). Therefore, inhibition of PI3K/Akt signalling pathway, as an effective way to suppress the activation or proliferation of fibroblasts, can be a novel therapeutic modality for PD-derived fibrosis.

Given the emerging importance of PI3K/Akt signalling in the pathogenesis of fibrosis, we have developed a new imidazo[1,2-a]pyridine derivative, HS-173, as a novel PI3K inhibitor. Although the anticancer effect of HS-173 has been reported in our previous study (19), the therapeutic efficacy of this compound against PD has not yet been evaluated. In the present study, we determined whether HS-173 exerts antifibrotic effects and the potential mechanisms underlying these processes in PD-derived primary fibroblasts. Our results showed that HS-173 alleviated fibrosis by promoting apoptosis and inhibiting the expression of fibrotic mediators such as collagen, $\alpha$-SMA and vimentin by blocking the PI3K/Akt pathway.

\section{Materials and methods}

Preparation of HS-173. Ethyl 6-(5-(phenylsulfonamido) pyridin-3-yl)imidazo[1,2-a]pyridine-3-carboxylate (HS-173) is a new PI3Ka inhibitor. This imidazopyridine derivative was synthesized as described in our previous study (20). For all in vitro studies, HS-173 was dissolved in dimethylsulfoxide (DMSO) before use.

Fibroblast cell culture. Plaque tissue was isolated from 4 PD patients who underwent surgical correction of their condition. All tissue donors provided informed consent and the procedures were approved by the internal review board of our university (21). The tissue was transferred to sterile vials containing Hank's balanced salt solution (Gibco, Carlsbad, CA) and washed three times in phosphate-buffered saline (PBS). The biopsy tissues were minced into $1-\mathrm{mm}^{2}$ pieces and incubated in a shaker with $12.5 \mathrm{ml}$ Dulbecco's modified Eagle's medium (DMEM) supplemented with $0.06 \%$ collagenase A (Sigma-Aldrich, St. Louis, MO) for $1 \mathrm{~h}$. The cells and tissue fragments were collected by centrifugation ( $400 \mathrm{x} \mathrm{g}$ for $5 \mathrm{~min}$ ), washed in fresh culture medium, and placed in 100-mm cell culture dishes (Falcon Becton-Dickinson Labware, Franklin Lakes, NJ) with DMEM supplemented with $10 \%$ fetal calf serum, penicillin $(100 \mathrm{U} / \mathrm{ml})$ and streptomycin $(100 \mathrm{mg} / \mathrm{ml})$. The dishes were incubated in a humidified incubator at $37^{\circ} \mathrm{C}$ with $5 \% \mathrm{CO}_{2}$.

Measurement of cell proliferation. Cell proliferation was measured with an MTT assay. Briefly, the fibroblasts were plated at a density of $2 \times 10^{4}$ cells/well in a 96-well plate and incubated for $24 \mathrm{~h}$. The medium was removed, and cells were treated with either $0.1 \%(\mathrm{v} / \mathrm{v})$ DMSO as a control or various concentrations of HS-173. After the cells were incubated for
$72 \mathrm{~h}, 20 \mu \mathrm{l}$ of an MTT solution $(2 \mathrm{mg} / \mathrm{ml})$ were added to each well and the plate was incubated for another $4 \mathrm{~h}$ at $37^{\circ} \mathrm{C}$. The resulting formazan crystals were dissolved in DMSO (200 $\mu \mathrm{l} / \mathrm{well}$ ) with constant shaking for $5 \mathrm{~min}$. Absorbance of the plate was then read with a microplate reader at $540 \mathrm{~nm}$. Three replicate wells were used for each analysis. The median inhibitory concentration $\left(\mathrm{IC}_{50}\right.$; defined as the drug concentration at which cell growth was inhibited by $50 \%$ ) was determined based on the dose-response curves.

Terminal deoxynucleotidyl transferase-mediated nick end labeling (TUNEL) assay. A TUNEL assay was performed using a commercially available kit (Chemicon, Temecula, CA) following the manufacturer's protocol. The cells were plated on an $18-\mathrm{mm}$ cover glass in DMEM at a density of $1 \times 10^{5}$ cells $/ \mathrm{ml}$ and incubated for $24 \mathrm{~h}$. The cells were then treated with $10 \mu \mathrm{M}$ HS-173 for $24 \mathrm{~h}$ before being fixed in an ice-cold mixture of acetic acid and ethanol. After the cells were washed with PBS, they were stained for TUNEL. The stained cells were examined under a fluorescence microscope for nuclear fragmentation.

Measurement of mitochondrial membrane potential. The fibroblasts were plated on 18-mm cover glasses in DMEM and incubated for $24 \mathrm{~h}$ so that approximately $70 \%$ confluence was reached. The cells were then incubated in the presence or absence of $5 \mu \mathrm{M}$ HS-173 for $2 \mathrm{~h}$ and then incubated with $5 \mu \mathrm{M}$ JC-1 fluorescence dye (MitoPT, Immunohistochemistry Technologies, Bloomington, $\mathrm{MN}$ ) for $20 \mathrm{~min}$ in a $\mathrm{CO}_{2}$ incubator. The slides were then washed twice with PBS and covered with Dabco (Sigma-Aldrich) before being viewed with a confocal laser scanning microscope (Olympus, Tokyo, Japan).

Western blot analysis. The cells were serum-starved for $24 \mathrm{~h}$ and then treated with various concentrations of HS-173 for $24 \mathrm{~h}$. The cells were washed three times with ice-cold PBS before being lysed in a buffer containing $1 \%$ Triton X-100, $1 \%$ Nonidet P-40, and the following protease and phosphatase inhibitors: aprotinin $(10 \mathrm{mg} / \mathrm{ml})$, leupeptin (10 mg/ml; ICN Biomedicals, Asse-Relegem, Belgium), phenylmethylsulfonyl fluoride $(1.72 \mathrm{mM}), \mathrm{NaF}(100 \mathrm{mM})$, $\mathrm{NaVO}_{3}(500 \mathrm{mM})$ and $\mathrm{Na}_{4} \mathrm{P}_{2} \mathrm{O}_{7}(500 \mathrm{mg} / \mathrm{ml}$; Sigma-Aldrich). Equal amounts of protein were separated using 8 or $12 \%$ sodium dodecyl sulfate-polyacrylamide gel electrophoresis and transferred onto nitrocellulose membranes. Protein transfer was confirmed using Ponceau S staining solution (Sigma-Aldrich). The blots were immunostained using the appropriate primary antibodies followed by secondary antibodies conjugated to horseradish peroxidase. Primary antibodies specific for the following factors were used: $\beta$-actin, collagen type I, collagen type IV, plasminogen activator inhibitor-1 (PAI-1), fibronectin, phosphorylated (p)-Akt (Abcam, Cambridge, UK), p-mTOR (e-bioscience), p-P70S6K, Akt, mTOR and P70S6K (Cell Signalling Technology, Beverly, MA). All secondary antibodies were purchased from Amersham Biosciences. Bands on the blots were visualized with the enhanced chemiluminescence plus system (Amersham Biosciences). Band intensities were quantified with ImageJ software. 
Immunofluorescence microscopy. The cells were plated on 18 -mm cover glasses in DMEM at a density of $1 \times 10^{5}$ cells/well and incubated for $24 \mathrm{~h}$. Next, the cells were incubated in the presence or the absence of $5 \mu \mathrm{M}$ HS-173 for $2 \mathrm{~h}$. The cells were washed with PBS and fixed in an acetic acid:ethanol (2:1) solution for $5 \mathrm{~min}$ at $-20^{\circ} \mathrm{C}$. Non-specific binding was blocked with $5 \%$ goat and horse serum/PBS for $1 \mathrm{~h}$ at room temperature, and the cells were then incubated with primary antibodies against vimentin, $\alpha$-SMA (Sigma-Aldrich), $p$-Akt (Abcam), p-mTOR, and p-4EBP1 (Cell Signaling Technology) in a humidified chamber. After washing twice in PBS, the cells were incubated with fluorescein-labeled secondary antibody (1:50; Dianova) in antibody dilution solution for $1 \mathrm{~h}$ at room temperature in the dark. The nuclei were stained with 4,6-diamidino-2-phenylindole (DAPI) in the dark for $30 \mathrm{~min}$ at room temperature. The slides were washed twice with PBS, covered with Dabco (Sigma-Aldrich), and examined with confocal laser scanning microscopy (Olympus) at 488 and $568 \mathrm{~nm}$.

Measurement of nucleus translocation. The cells were plated on 18-mm cover glasses in DMEM and grown to approximately $70 \%$ confluence for $24 \mathrm{~h}$. Next, the cells were serum-starved for $24 \mathrm{~h}$ and then pretreated with $10 \mu \mathrm{M}$ HS-173 for $1 \mathrm{~h}$. The fibroblasts were then treated with $20 \mathrm{ng} / \mathrm{ml}$ TGF- $\beta 1$ (R\&D Systems) for $4 \mathrm{~h}$. The cells were washed with PBS and fixed in an acetic acid:ethanol (2:1) solution for $5 \mathrm{~min}$ at $-20^{\circ} \mathrm{C}$. Non-specific binding was blocked in $5 \%$ goat and horse serum/PBS for $1 \mathrm{~h}$ at room temperature, and the cells were then incubated with primary antibodies against smad2/3 (Cell Signaling Technology) in a humidified chamber. After washing twice in PBS, the cells were incubated with fluorescein-labeled secondary antibody (1:200; Dianova) in $1.5 \%$ horse serum/PBS at room temperature in the dark for $1 \mathrm{~h}$ at $37^{\circ} \mathrm{C}$. The nuclei were stained with DAPI in the dark for $30 \mathrm{~min}$ at room temperature. The slides were washed twice with PBS, covered with Dabco (Sigma-Aldrich), and examined with confocal laser scanning microscopy (Olympus) at 488 and at $568 \mathrm{~nm}$.

Statistical analysis. Data are expressed as the mean $\pm \mathrm{SD}$, and analyzed with the ANOVA and unpaired Student's t-test. A p-value of $\leq 0.05$ was considered statistically significant. Statistical calculations were performed using SPSS software for the Windows operating system (version 10.0; SPSS, Chicago, IL).

\section{Results}

$H S-173$ inhibits the proliferation of $P D$-derived primary fibroblasts. We first examined the effect of HS-173 on the proliferation and viability of fibroblasts derived from human PD plaques. The cells were exposed to various concentrations $(0,0.1,0.5,1,5,10$ and $50 \mu \mathrm{M})$ of HS-173 for $72 \mathrm{~h}$. As shown in Fig. 1A, HS-173 inhibited fibroblast growth in a dose-dependent manner starting at a concentration of $0.5 \mu \mathrm{M}$. In particular, 10 and $50 \mu \mathrm{M}$ of $\mathrm{HS}-173$ significantly reduced cell growth by 40 and $80 \%$, respectively.

HS-173 induces apoptotic cell death. To assess the apoptotic effects of HS-173 on PD-derived primary fibroblasts,

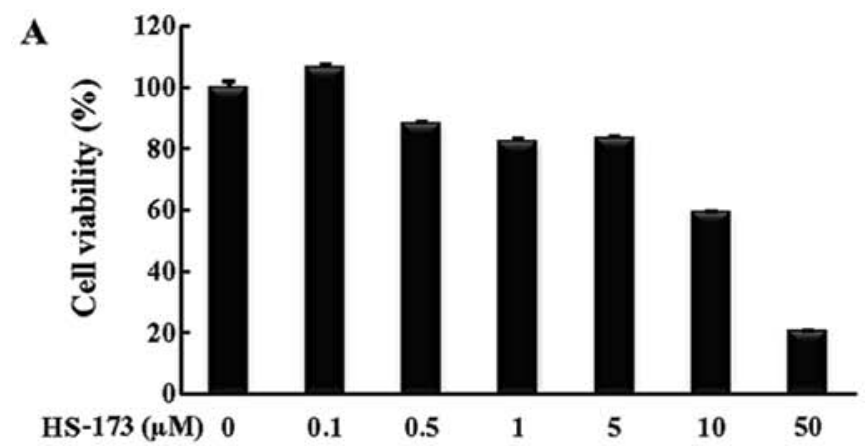

B
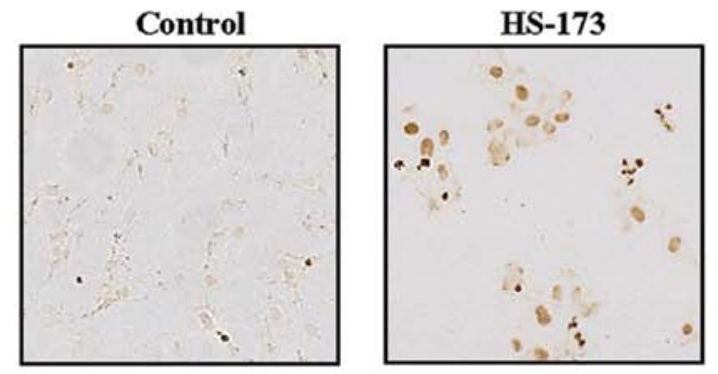

C
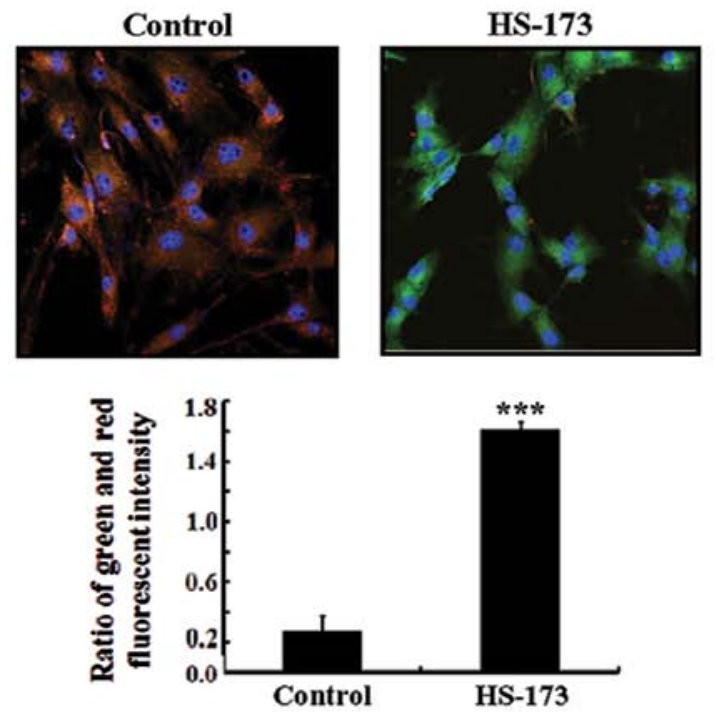

Figure 1. Effect of HS-173 on the proliferation and apoptosis of PD-derived fibroblasts. (A) Cytotoxic effects of HS-173 on PD-derived fibroblasts were measured with an MTT assay. After the fibroblasts were seeded in a 96-well culture plate and incubated for $24 \mathrm{~h}$, the cells were treated with various concentrations of HS-173 or $0.1 \%$ dimethyl sulfoxide (DMSO) as the control. After treatment with HS-173 for $72 \mathrm{~h}$, the cells were subjected to an MTT assay. Results are expressed as the percent of cell proliferation relative to that of the control. Data are represented as the mean \pm SD from triplicate wells. (B) The induction of apoptosis by the treatment of $10 \mu \mathrm{M}$ HS-173 for $24 \mathrm{~h}$ was evaluated by TUNEL and the cells were photographed. (C) Mitochondria membrane potential was measured by JC-1 staining in cells treated with HS-173 $(5 \mu \mathrm{M})$ for $2 \mathrm{~h}$. Data are presented as the mean \pm SD from triplicate wells. ${ }^{* * * *} \mathrm{p}<0.001$ vs. control.

we performed a TUNEL assay. When treated with $10 \mu \mathrm{M}$ HS-173, the fibroblasts developed morphological features characteristic of apoptotic cells. As shown in Fig. 1B, DNA fragmentation was observed by TUNEL in the cells treated with HS-173. Since the loss of mitochondrial membrane potential $\left(\psi_{\mathrm{m}}\right)$ is a hallmark for apoptosis, we also conducted JC-1 staining to identify the impact of HS-173 on $\psi_{\mathrm{m}}$ (Fig. 1C). Heterogeneous staining of the cytoplasm with both red and 
A

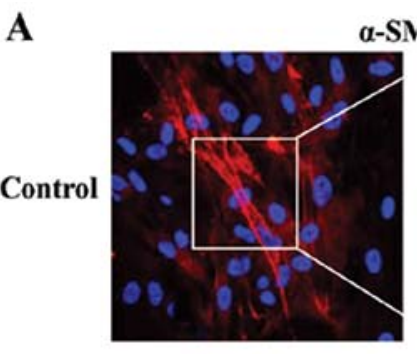

-SMA
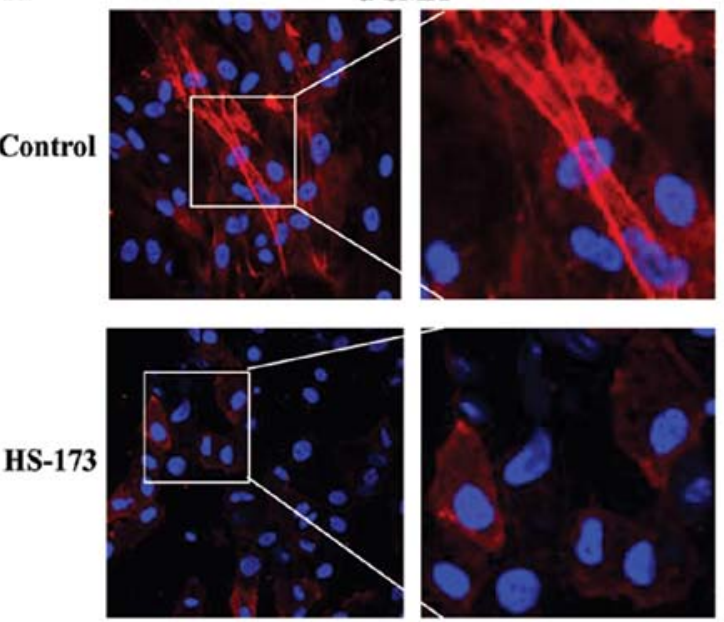

B
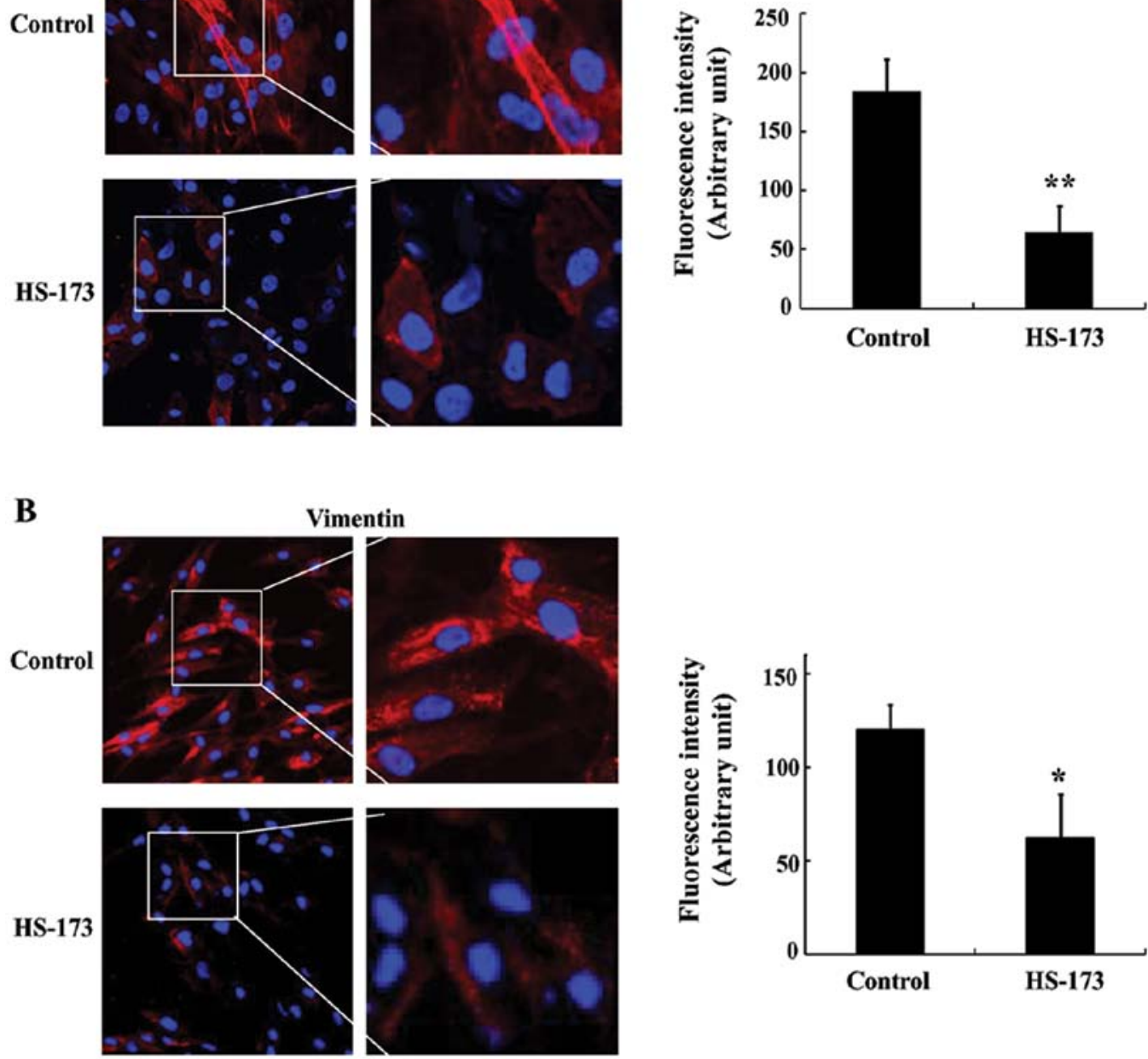

Figure 2. Inhibitory effect of HS-173 on the expression of $\alpha$-SMA and vimentin in PD-derived fibroblasts. The fibroblasts were treated with or without HS-173 $(1 \mu \mathrm{M})$ for $2 \mathrm{~h}$. The expression of (A) $\alpha$-SMA and (B) vimentin was evaluated by immunofluorescence. Data are presented as the mean \pm SD from the three experiments. ${ }^{*} \mathrm{p}<0.05$ and ${ }^{* *} \mathrm{p}<0.01$ vs. the control.

green fluorescence coexisting in the same cell was observed in the control cells. Treatment with HS-173 $(5 \mu \mathrm{M})$ decreased the red fluorescence in the fibroblasts and frequent clusters of mitochondria were seen. Exposure to HS-173 induced marked changes in $\psi_{\mathrm{m}}$ as evident from the disappearance of red fluorescence or increased green fluorescence in most cells. These results showed that HS-173 induced apoptotic cell death with the loss of $\Delta \psi_{\mathrm{m}}$ in PD-derived fibroblast cells.

HS-173 has anti-fibrotic effects in PD-derived fibroblasts. In order to determine whether HS-173 triggers characteristics of fibroblasts, we stained positive fibroblast markers in PD-derived fibroblasts. As shown in Fig. 2A and B, PD-derived fibroblasts highly expressed fibroblast-positive makers such as $\alpha$-SMA and vimentin. In contrast, the expression of $\alpha$-SMA and vimentin in cells treated with HS-173 was decreased compared to the untreated cells. In order to confirm the anti-fibrosis effect of HS-173, we performed western blot analysis. The fibroblasts were serum-starved for $24 \mathrm{~h}$ and treated with HS-173 ( 0 to $20 \mu \mathrm{M}$ ) for $24 \mathrm{~h}$. As shown in Fig. 3A, the expression of PAI-1, fibronectin, collagen type I and collagen type IV was decreased by HS-173 in a dose-dependent manner. Our results revealed that HS-173 had an anti-fibrotic effect by reducing the expression of fibrosis mediators such as $\alpha$-SMA, vimentin, PAI-1, fibronectin and collagen in PD-derived fibroblasts.

$H S-173$ suppresses the expression of $s m a d 2 / 3$ in TGF- $\beta 1$-treated PD-derived fibroblasts. In the TGF- $\beta$ signalling pathway, TGF- $\beta$ binds to its receptor on the plasma membrane and smad $2 / 3$ moves from the cytoplasm to nucleus resulting in the upregulation of transcription. We investigated whether HS-173 suppressed TGF- $\beta$-induced nuclear translocation of smad $2 / 3$ in PD-derived fibroblasts. Fibroblasts treated with TGF- $\beta 1$ showed high expression of $\operatorname{smad} 2 / 3$ in the nucleus compared to the control cells (Fig. 4). Interestingly, HS-173 significantly decreased the nuclear translocation of $\operatorname{smad} 2 / 3$ in TGF- $\beta$-treated fibroblasts. Moreover, the cells treated with HS-173 showed low expression of smad2/3 not only in the nucleus but also in the cytoplasm. Our results demonstrated 

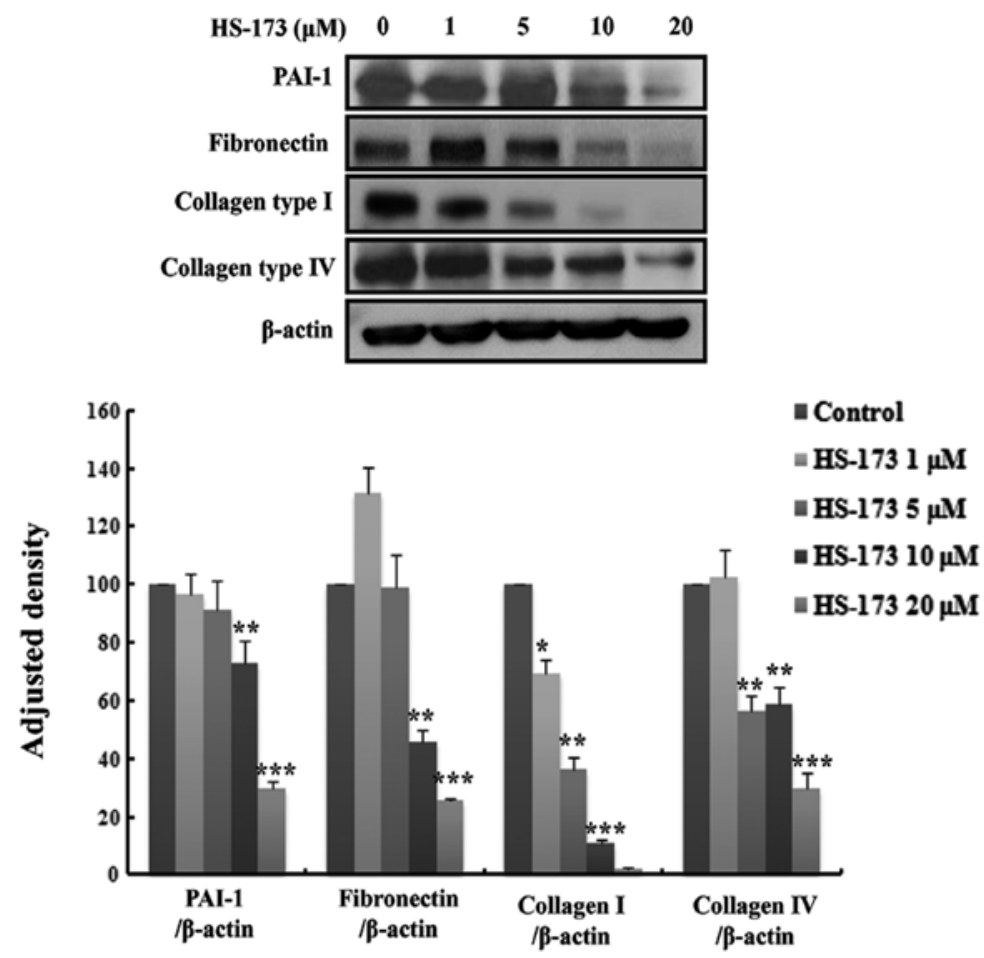

Figure 3. Anti-fibrotic effect of HS-173 on PD-derived fibroblasts. The expression of PAI-1, fibronectin, collagen type I or collagen type IV was measured by western blot analysis after treatment with HS-173 at the indicated doses for $24 \mathrm{~h}$. Band intensities were quantified with ImageJ software. Data are presented as the mean \pm SD from three experiments. ${ }^{*} \mathrm{p}<0.05,{ }^{* *} \mathrm{p}<0.01$ and ${ }^{* * *} \mathrm{p}<0.001$ vs control.
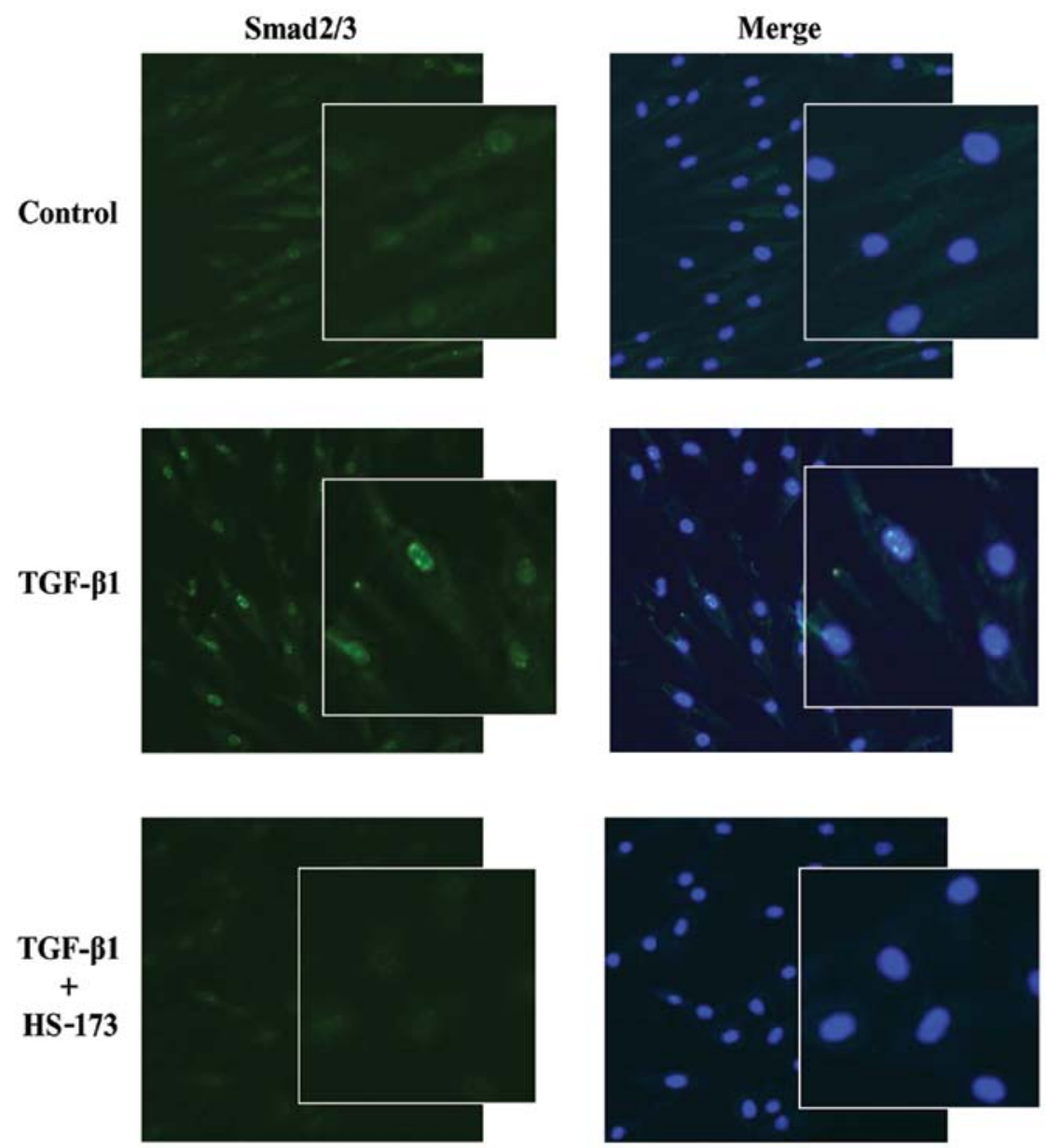

Figure 4. Effect of HS-173 on smad2/3 nuclear translocation in TGF- $\beta$-treated fibroblasts. The expression of smad $2 / 3$ was measured by immunofluorescence. The cells were pre-treated with HS-173 $(10 \mu \mathrm{M})$ for $1 \mathrm{~h}$ and then treated with $20 \mathrm{ng} / \mathrm{ml}$ TGF- $\beta$ for $4 \mathrm{~h}$. DAPI was used to counterstain the nucleus. 


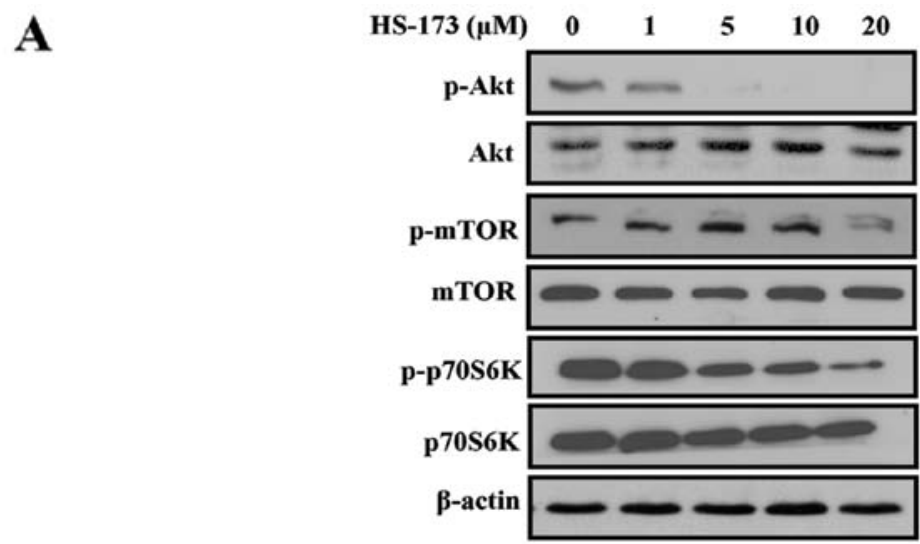

B
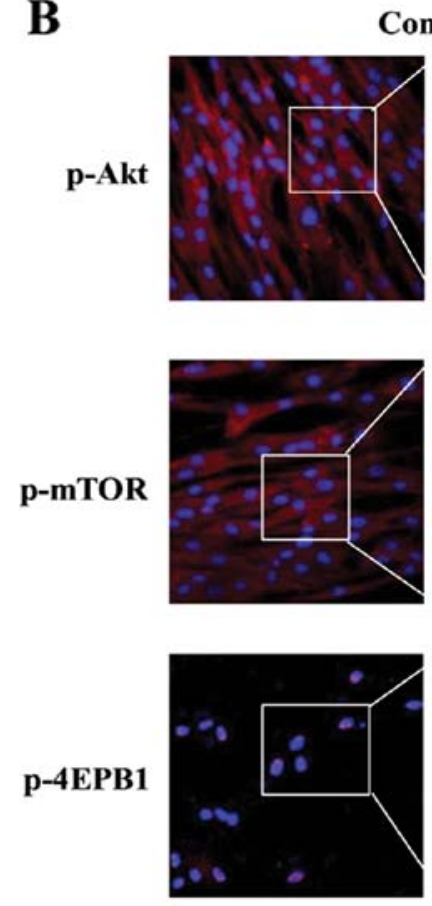
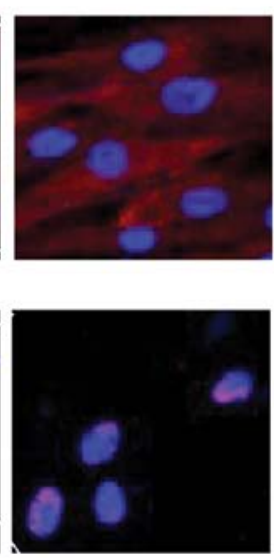

Control

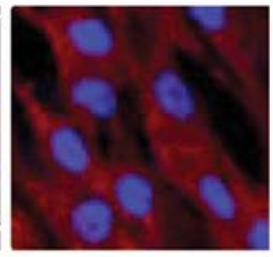

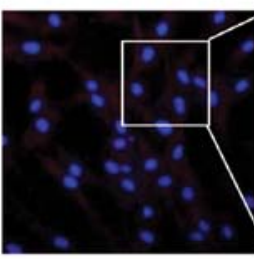

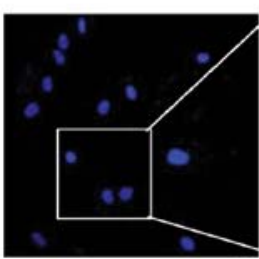

HS-173
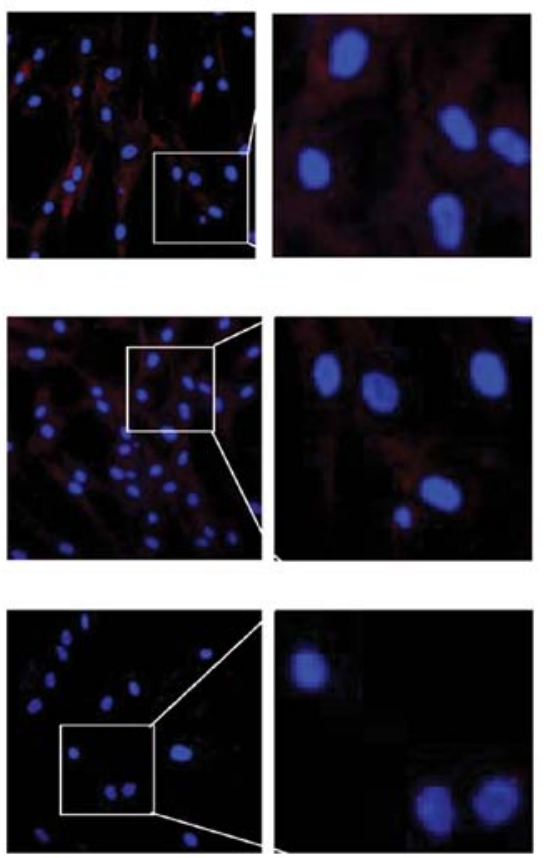

Figure 5. Effect of HS-173 on the PI3K/Akt/mTOR pathway in PD-derived fibroblasts. (A) The fibroblasts were treated with various concentrations (1-20 $\mu \mathrm{M})$ of HS-173 for $24 \mathrm{~h}$. Western blot analysis for p-Akt, p-mTOR or p-P70S6K was then performed. (B) The cells were treated with HS-173 (1 $\mu \mathrm{M}$ ) for $2 \mathrm{~h}$. The expression of p-Akt, p-mTOR and p-4EBP1 was evaluated by immunofluorescence.

that HS-173 inhibited the translocation of $\operatorname{smad} 2 / 3$ in fibroblasts exposed to TGF- $\beta$.

HS-173 inhibits the PI3K/Akt/mTOR signalling pathway in PD-derived fibroblasts. Since HS-173 is a novel PI3K inhibitor, we determined whether this compound blocked the PI3K/Akt/mTOR pathway in PD-derived fibroblasts. Fibroblasts were treated with various concentrations of HS-173 and the protein expression of PI3K/Akt/mTOR signalling factors was observed by western blot analysis. We found that the expression of p-Akt, p-mTOR and p-P70S6K was obviously inhibited by HS-173 in PD-derived fibroblasts (Fig. 5A). To confirm these results, we performed immunofluorescence analyses. Consistent with the western blot analysis data, we found that HS-173 effectively blocked the PI3K/Akt/mTOR pathway by decreasing the levels of p-mTOR, p-Akt and p-4EBP1 in PD-derived fibroblasts (Fig. 5B).

\section{Discussion}

Surgical correction remains the gold standard for treating PD in cases of severe deformity. However, surgical correction is available in limited cases because it is highly invasive procedure and may give rise to shortening of the penis or recurrence of penile curvature as a complication after surgery $(22,23)$. Currently, a variety of oral, injectable and topical agents are available for the treatment PD $(24,25)$. Unfortunately, most of medical treatment options did not demonstrate conclusive effects in PD patients, although these therapies have been proven to be effective at preclinical levels.

Based on recent studies showing that PI3K/Akt signalling is involved in the development and progression of fibrogenesis during cell proliferation and collagen production $(26,27)$, we synthesized HS-173, a novel PI3K inhibitor and evaluated its anti-fibrosis effects on PD-derived fibroblasts along with the underlying mechanisms. Our study showed 
that HS-173 exerted anti-fibrotic effects by decreasing the expression of collagen, $\alpha$-SMA and vimentin in PD-derived primary fibroblasts. Additionally, this compound inhibited the growth and proliferation of the cells. Taken together, our findings suggest that the anti-fibrotic effects of HS-173 were mediated by inhibition of the PI3K/Akt signalling pathway.

$\mathrm{PD}$ is characterized by the proliferation of tunical fibroblasts, subsequent differentiation of these cells into contractile myofibroblasts and excessive deposition of collagen (28). Aberrant proliferation of PD fibroblasts has also been detected in PD patients (28). To inhibit PD fibroblast proliferation, many agents with anti-fibrotic potential have been employed to downregulate or neutralize proliferative, fibrogenic and contractile responses of myofibroblasts (29). Thus, we first investigated the anti-proliferation effect of HS-173 on PD-derived fibroblasts. In our study, HS-173 inhibited the growth of PD-derived fibroblasts by $20-80 \%$ starting at a concentration of $0.5 \mu \mathrm{M}$. HS-173 did not only inhibit cell growth and proliferation, but also induced apoptosis in the PD-derived fibroblasts. This is of particular interest because there is an emerging evidence showing that the process of apoptosis is defective in PD plaques. It has been demonstrated that the rate of proliferation of fibroblasts derived from plaque tissue is faster than that of apoptosis (30). Additionally, PD plaque-derived fibroblasts have higher DNA production levels than control cells (31). Since the biological features of apoptosis include DNA fragmentation and increase mitochondrial membrane permeability (32), we identified the apoptotic effects of HS-173 using the TUNEL assay and JC-1 staining. Our result showed that HS-173 induced apoptosis by increasing DNA fragmentation. In addition, a loss of $\Delta \psi_{\mathrm{m}}$ following HS-173 treatment led to the induction of apoptosis in PD-derived fibroblasts.

Considering the above results, the effect of HS-173 on proliferation and apoptosis was expected to influence anti-fibrotic responses in PD-derived fibroblasts. Furthermore, previous studies have reported that the fibroblasts secrete ECM-related proteins such as collagen and proteoglycans, and in turn the ECM itself regulates fibroblast proliferation, apoptosis and migration $(27,28)$. We therefore determined whether HS-173 inhibited the expression of $\alpha$-SMA, vimentin, PAI-1, fibronectin and collagen type I/IV. As expected, HS-173 reduced the expression of fibrosisrelated mediators in PD-derived fibroblasts. These results were consistent with those of Mikulec et al showing that tamoxifen used to treat PD inhibits the proliferation of fibroblasts and decreases collagen synthesis (33). Our findings suggest that HS-173 exerts anti-fibrotic effects by regulating the proliferation and apoptosis of PD-derived fibroblasts.

PI3K is well known to control many cellular functions such as proliferation, survival and migration (14). Recently, the PI3K/Akt pathway has been reported to represent a mechanism critical for the proliferation of fibroblasts in various organs including the lung, liver and heart $(26,34,35)$. Furthermore, inhibition of PI3K/Akt activation decreases both fibroblast proliferation and differentiation into myofibroblasts in human lung (36). Thus, PI3K signalling is activated in fibroblasts and correlates with collagen production $(34,37)$. If PI3K is targeted, the expression or activation of various fibrogenic mediators might be reduced. In this regard, the PI3K/Akt signalling pathway could represent a therapeutic target for PD-derived fibrosis. However, it has been not reported whether this signalling pathway contributes to the regulation of PD.

We therefore evaluated the activation of the PI3K/Akt signalling pathway in PD-derived fibroblasts and suppression of this pathway by HS-173. We observed that the expression of Akt, mTOR and P70S6K was notably increased in PD-derived fibroblasts, indicating that the PI3K signalling pathway was activated in PD-derived fibroblasts. On the contrary, HS-173 significantly inhibited PI3K signalling. These results led us to hypothesize that the anti-fibrotic effects of HS-173 might be mediated by inhibition of the PI3K/Akt pathway. It was previously reported that LY294002 (a pan-inhibitor of PI3K) abrogates cell proliferation as well as $\alpha$-SMA expression and collagen synthesis in embryonic fibroblasts (38). This is consistent with data from our present study showing that PI3K inhibition by HS-173 decreased the proliferation of PD-derived fibroblasts and collagen expression.

In conclusion, the present study shows that HS-173, targeting the PI3K/Akt pathway, has an anti-fibrotic action. To our knowledge, this is the first report showing that inhibition of PI3K/Akt signalling pathway may be potentially useful for the treatment of PD although the effect remains to be evaluated in vivo.

\section{Acknowledgements}

This study was supported by a grant from the Korea Health Technology R\&D Project, Ministry of Health and Welfare, Republic of Korea (J.-K.S. A110076).

\section{References}

1. Schwarzer U, Sommer F, Klotz T, Braun M, Reifenrath B and Engelmann U: The prevalence of Peyronie's disease: results of a large survey. BJU Int 88: 727-730, 2001.

2. Ralph D, Gonzalez-Cadavid N, Mirone V, Perovic S, Sohn M, Usta $\mathrm{M}$ and Levine L: The management of Peyronie's disease: evidence-based 2010 guidelines. J Sex Med 7: 2359-2374, 2010.

3. Mulhall JP, Creech SD, Boorjian SA, Ghaly S, Kim ED, Moty A, Davis R and Hellstrom W: Subjective and objective analysis of the prevalence of Peyronie's disease in a population of men presenting for prostate cancer screening. J Urol 171: 2350-2353, 2004.

4. Dean RC and Lue TF: Physiology of penile erection and pathophysiology of erectile dysfunction. Urol Clin North Am 32: 379-395, 2005.

5. Gonzalez-Cadavid NF and Rajfer J: Mechanisms of disease: new insights into the cellular and molecular pathology of Peyronie's disease. Nat Clin Pract Urol 2: 291-297, 2005.

6. Haag SM, Hauck EW, Szardening-Kirchner C, Diemer T, Cha ES, Weidner W and Eickelberg O: Alterations in the transforming growth factor (TGF)-beta pathway as a potential factor in the pathogenesis of Peyronie's disease. Eur Urol 51: 255-261, 2007.

7. Domes T, De Young L, O'Gorman DB, Gan BS, Bella AJ and Brock G: Is there a role for proteomics in Peyronie's disease? J Sex Med 4: 867-877, 2007.

8. El-Sakka AI, Hassoba HM, Chui RM, Bhatnagar RS, Dahiya R and Lue TF: An animal model of Peyronie's-like condition associated with an increase of transforming growth factor beta mRNA and protein expression. J Urol 158: 2284-2290, 1997.

9. Assinder SJ, Dong Q, Kovacevic Z and Richardson DR: The TGF-beta, PI3K/Akt and PTEN pathways: established and proposed biochemical integration in prostate cancer. Biochem $\mathrm{J}$ 417: 411-421, 2009.

10. Danielpour D: Functions and regulation of transforming growth factor-beta (TGF-beta) in the prostate. Eur J Cancer 41: 846-857, 2005 
11. Cantley LC: The phosphoinositide 3-kinase pathway. Science 296: 1655-1657, 2002.

12. Carracedo A and Pandolfi PP: The PTEN-PI3K pathway: of feedbacks and cross-talks. Oncogene 27: 5527-5541, 2008.

13. Andre E, Gazzieri D, Bardella E, Ferreira J, Mori MA, Saul VV, Bader M, Calixto JB, De Giorgio R, Corinaldesi R, Geppetti P and Trevisani M: Expression and functional pharmacology of the bradykinin B1 receptor in the normal and inflamed human gallbladder. Gut 57: 628-633, 2008.

14. Reif S, Lang A, Lindquist JN, Yata Y, Gabele E, Scanga A, Brenner DA and Rippe RA: The role of focal adhesion kinasephosphatidylinositol 3-kinase-akt signaling in hepatic stellate cell proliferation and type I collagen expression. J Biol Chem 278: 8083-8090, 2003.

15. Gentilini A, Marra F, Gentilini $P$ and Pinzani $M$ : Phosphatidylinositol-3 kinase and extracellular signal-regulated kinase mediate the chemotactic and mitogenic effects of insulin-like growth factor-I in human hepatic stellate cells. J Hepatol 32: 227-234, 2000

16. Kulik G, Klippel A and Weber MJ: Antiapoptotic signalling by the insulin-like growth factor I receptor, phosphatidylinosito 3-kinase, and Akt. Mol Cell Biol 17: 1595-1606, 1997.

17. Kim AH, Khursigara G, Sun X, Franke TF and Chao MV: Akt phosphorylates and negatively regulates apoptosis signal-regulating kinase 1. Mol Cell Biol 21: 893-901, 2001.

18. Coffer PJ, Jin J and Woodgett JR: Protein kinase B (c-Akt) a multifunctional mediator of phosphatidylinositol 3-kinase activation. Biochem J 335 (Pt 1): 1-13, 1998.

19. Lee H, Jung KH, Jeong Y, Hong S and Hong SS: HS-173, a novel phosphatidylinositol 3-kinase (PI3K) inhibitor, has antitumor activity through promoting apoptosis and inhibiting angiogenesis. Cancer Lett 328: 152-159, 2013.

20. Hong S, Lee S, Kim B, Lee H and Hong SS: Discovery of new azaindole-based PI3Kalpha inhibitors: apoptotic and antiangiogenic effect on cancer cells. Bioorg Med Chem Lett 20: 7212-7215, 2010

21. Piao S, Choi MJ, Tumurbaatar M, Kim WJ, Jin HR, Shin SH, Tuvshintur B, Yin GN, Song JS, Kwon MH, Lee SJ, Han JY, Kim SJ, Ryu JK and Suh JK: Transforming growth factor (TGF)-beta type I receptor kinase (ALK5) inhibitor alleviates profibrotic TGF-beta1 responses in fibroblasts derived from Peyronie's plaque. J Sex Med 7: 3385-3395, 2010.

22. LaRochelle JC and Levine LA: A survey of primary-care physicians and urologists regarding Peyronie's disease. J Sex Med 4: 1167-1173, 2007 .

23. Sasso F, Gulino G, Falabella R, D'Addessi A, Sacco E, D'Onofrio A and Bassi PF: Peyronie's disease: lights and shadows. Urol Int 78: 1-9, 2007.

24. Shindel AW and Lue TF: Peyronie's disease: past, present, future? Curr Urol Rep 9: 425-427, 2008.

25. Hauck EW, Diemer T, Schmelz HU and Weidner W: A critical analysis of nonsurgical treatment of Peyronie's disease. Eur Urol 49: 987-997, 2006.
26. Son G, Hines IN, Lindquist J, Schrum LW and Rippe RA Inhibition of phosphatidylinositol 3-kinase signaling in hepatic stellate cells blocks the progression of hepatic fibrosis. Hepatology 50: 1512-1523, 2009.

27. Conte E, Fruciano M, Fagone E, Gili E, Caraci F, Iemmolo M, Crimi $\mathrm{N}$ and Vancheri C: Inhibition of PI3K prevents the proliferation and differentiation of human lung fibroblasts into myofibroblasts: the role of class I P110 isoforms. PLoS One 6: e24663, 2011.

28. Abdel-Hamid IA and Anis T: Peyronie's disease: perspectives on therapeutic targets. Expert Opin Ther Targets 15: 913-929, 2011.

29. Bobustuc GC, Smith JS, Maddipatla S, Jeudy S, Limaye A, Isley B, Caparas ML, Constantino SM, Shah N, Baker CH, Srivenugopal KS, Baidas S and Konduri SD: MGMT inhibition restores ERalpha functional sensitivity to antiestrogen therapy. Mol Med 18: 913-929, 2012

30. Anderson MS, Shankey TV, Lubrano T and Mulhall JP: Inhibition of Peyronie's plaque fibroblast proliferation by biologic agents. Int J Impot Res 12 (Suppl 3): S25-S31, 2000.

31. Mulhall JP, Nicholson B, Pierpaoli S, Lubrano T and Shankey TV: Chromosomal instability is demonstrated by fibroblasts derived from the tunica of men with Peyronie's disease. Int J Impot Res 16: 288-293, 2004

32. Elmore S: Apoptosis: a review of programmed cell death. Toxicol Pathol 35: 495-516, 2007.

33. Mikulec AA, Hanasono MM, Lum J, Kadleck JM, Kita M and Koch RJ: Effect of tamoxifen on transforming growth factor beta1 production by keloid and fetal fibroblasts. Arch Facial Plast Surg 3: 111-114, 2001.

34. He Z, Gao Y, Deng Y, Li W, Chen Y, Xing S, Zhao X, Ding J and Wang X: Lipopolysaccharide induces lung fibroblast proliferation through Toll-like receptor 4 signaling and the phosphoinositide3-kinase-Akt pathway. PLoS One 7: e35926, 2012.

35. Voloshenyuk TG, Landesman ES, Khoutorova E, Hart AD and Gardner JD: Induction of cardiac fibroblast lysyl oxidase by TGF-beta1 requires PI3K/Akt, Smad3, and MAPK signaling. Cytokine 55: 90-97, 2011.

36. Xia H, Khalil W, Kahm J, Jessurun J, Kleidon J and Henke CA: Pathologic caveolin-1 regulation of PTEN in idiopathic pulmonary fibrosis. Am J Pathol 176: 2626-2637, 2010.

37. Marra F Gentilini A, Pinzani M, Choudhury GG, Parola M, Herbst H, Dianzani MU, Laffi G, Abboud HE and Gentilini P: Phosphatidylinositol 3-kinase is required for platelet-derived growth factor's actions on hepatic stellate cells. Gastroenterology 112: 1297-1306, 1997.

38. Foukas LC, Berenjeno IM, Gray A, Khwaja A and Vanhaesebroeck B: Activity of any class IA PI3K isoform can sustain cell proliferation and survival. Proc Natl Acad Sci USA 107: 11381-11386, 2010 